\title{
Antidepressant, anxiolytic and procognitive effects of rivastigmine and donepezil in the chronic mild stress model in rats
}

\author{
Mariusz Papp $^{1} \cdot$ Piotr Gruca $^{1}$ - Magdalena Lason-Tyburkiewicz ${ }^{1} \cdot$ Paul Willner $^{2}$
}

Received: 17 August 2015 / Accepted: 4 January 2016 / Published online: 15 January 2016

(C) The Author(s) 2016. This article is published with open access at Springerlink.com

\begin{abstract}
Background The treatment of depression in old age is complicated by frequent co-morbidity with cognitive impairment. Anti-dementia drugs have some efficacy to improve cognitive performance and there is an inconsistent literature regarding the effect of such drugs on depressive symptoms. Here, we have investigated whether anti-dementia drugs would have antidepressant-like and pro-cognitive effects in a wellvalidated animal model of depression and cognitive impairment, chronic mild stress (CMS).

Methods Rats were subjected to CMS for a total of 8 weeks. After 2 weeks, subgroups of stressed and non-stressed animals were treated daily, for 5 weeks followed by 1 week of drug withdrawal, with vehicle, imipramine $(10 \mathrm{mg} / \mathrm{kg})$, rivastigmine $(2 \mathrm{mg} / \mathrm{kg})$, donepezil $(0.3 \mathrm{mg} / \mathrm{kg})$ or memantine $(5 \mathrm{mg} / \mathrm{kg}$ ). Sucrose intake was tested weekly, and animals were also tested in the elevated plus maze (at week 7) and in an object recognition task (at weeks 7 and 8).

Results CMS decreased sucrose intake, had an anxiogenic effect in the elevated plus maze, and impaired performance in the object recognition test. Imipramine, rivastigmine and donepezil normalized performance in all three tests. Memantine had anxiolytic and pro-cognitive effects, but did not reverse CMS-induced anhedonia.

Discussion The fact that all three anti-dementia drugs reversed CMS-induced cognitive impairment and that
\end{abstract}

Mariusz Papp

nfpapp@cyfronet.pl

1 Institute of Pharmacology, Polish Academy of Sciences, 12 Smetna Street, 31-343 Krakow, Poland

2 Department of Psychology, Swansea University, Swansea, UK cholinesterase inhibitors, but not memantine, have antidepressant-like effects in this model suggest that different mechanisms may underlie CMS-induced anhedonia and cognitive impairment. We discuss the clinical implications of these findings.

Keywords Chronic mild stress $\cdot$ Anhedonia $\cdot$ Object recognition $\cdot$ Cholinesterase inhibitors · Rivastigmine . Donepezil $\cdot$ Memantine $\cdot$ Imipramine $\cdot$ Rat

\section{Introduction}

The treatment of depression has advanced little in the half century since the introduction of antidepressant drugs into clinical practice: while newer drugs generally have an improved side effect profile and some of them have a slightly greater efficacy than older antidepressants, a substantial proportion of patients remain refractory to treatment and the onset of action remains unacceptably slow (Trivedi et al. 2006; Holtzheimer and Mayberg 2011; Belzung 2014). However, recent experience with experimental treatments such as ketamine (Zarate et al. 2006a, b; Diazgranados et al. 2010) and deep brain stimulation (Mayberg 2009; Hamani et al. 2011) provides evidence that the treatment-resistant depression is in principle treatable (Willner et al. 2014).

The treatment of depression in old age is particularly problematic because in addition to their general limitations, antidepressants are less effective in older patients (Kok et al. 2012; Calati et al. 2013). This in part reflects the frequent co-morbidity of old-age depression with cognitive decline (Weisenbach et al. 2012; Aziz and Steffens 2013). In order to address this co-morbidity, a number of studies have been conducted in which anti-dementia drugs were used to augment antidepressant treatment in later life. Positive antidepressant 
effects of augmentation with acetyl cholinesterase (AChE) inhibitors have been reported (e.g. Cummings et al. 2006; Rozzini et al. 2007; Spalletta et al. 2013) but there are also negative reports (e.g. Holtzheimer et al. 2008; Reynolds et al. 2011) and the overall picture is not encouraging (McDermott and Gray 2012). Another anti-dementia drug memantine, an NMDA receptor antagonist, has generally proved ineffective as an antidepressant (Sani et al. 2012), at least in unipolar depression, when used either as antidepressant augmentation (e.g. Muhonen et al. 2008; Smith et al. 2013; Omranifard et al. 2014) or as monotherapy for late life depression (e.g. Zarate et al. 2006a, b; Lenze et al. 2012).

Despite these discouraging clinical findings, we considered that, since some of the studies of cholinesterase inhibitors did report positive antidepressant effects, it might be worthwhile to ask whether such effects could be detected in a wellvalidated animal model of depression, since this would enable investigation of underlying mechanisms, leading, potentially, to refinement of the therapeutic approach. We have therefore investigated the effects, in the chronic mild stress model (Willner 1997, 2005), of two acetylcholinesterase (AChE) inhibitors that are in clinical use as anti-dementia drugs, donepezil and rivastigmine. We also studied memantine, which, on the basis of the unequivocal clinical literature, was predicted to be ineffective as an antidepressant. In order to confirm bio-availability of the three drugs, and appropriate dose selection, their effects were also examined in tests of anxiety (the elevated plus-maze) and cognition (novel object recognition). A number of studies have reported that CMS, in addition to its anhedonic effect, also impairs cognitive performance (Orsetti et al. 2007; Elizalde et al. 2008; Briones et al. 2012; Solas et al. 2013). However, other than one small and uninterpretable study of memantine (Quan et al. 2011), and a second study in which donepezil improved memory to a similar extent in CMS and control mice (Maratha and Mahadevan 2012), we have been unable to identify previous studies in which the ability of anti-dementia agents to reverse these deficits was investigated. Therefore, this study also served to investigate whether donepezil, rivastigmine and memantine would reverse a CMS-induced cognitive impairment. The tricyclic antidepressant imipramine was also tested, as a positive control.

\section{Methods}

\section{Subjects}

A total of 96 male Wistar rats (Charles River, Germany) were brought into the laboratory 1 month before the start of the experiment. The animals were 3 months old at the start of the stress procedure and 5 months old at the end. Body weights were measured at four time points during the course of the experiment (see below). Except as described below, the animals were singly housed with food and water freely available, and were maintained on a 12-h light/dark cycle (lights on at $08.00 \mathrm{~h}$ ) under conditions of constant temperature (22 $\left.\pm 2{ }^{\circ} \mathrm{C}\right)$ and humidity $(50 \pm 5 \%)$. Behavioural experiments were conducted between 09.00 and $15.00 \mathrm{~h}$. All procedures used in this study were conducted in compliance with the rules and principles of the 86/609/EEC Directive, and were approved by the Bioethical Committee of the Institute of Pharmacology, Polish Academy of Sciences, Krakow, Poland.

\section{Chronic mild stress (CMS) procedure}

Following 2 weeks of adaptation to laboratory and housing conditions, animals were adapted to consumption of a $1 \%$ sucrose solution in 7 weekly 1 -h baseline tests following $14 \mathrm{~h}$ food and water deprivation. Singly housed animals in their home cages were presented with $200 \mathrm{ml}$ of sucrose in a $300 \mathrm{ml}$ polythene bottle equipped with a rubber bung and a stainless steel ball-tip nozzle (North Kent Plastics, UK). Fresh sucrose solutions were made up for each test; following the test, bottles were washed using warm tap water and no detergent. Sucrose intake was calculated by weighing bottles before and after the test (Fig. 1).

On the basis of their sucrose intakes in the final baseline test, the animals were divided into two matched groups: control (CON) and to-be-stressed (STR). Control animals were housed in separate rooms and had no contact with the stressed animals; they were deprived of food and water for $14 \mathrm{~h}$ preceding each sucrose test, but otherwise, food and water were freely available in their home cage. Sucrose tests were administered for $1 \mathrm{~h}$ weekly, from 10.00 to $11.00 \mathrm{~h}$ on Tuesdays; other than food/water deprivation, no stressors were administered in the previous $24 \mathrm{~h}$. Stress was administered for a total of 8 weeks, and consisted of the following: two periods of food or water deprivation, two periods of $45^{\circ}$ cage tilt, two periods of intermittent illumination (lights on and off every $2 \mathrm{~h}$ ), two periods of soiled cage ( $250 \mathrm{ml}$ water in sawdust bedding), one period of paired housing, two periods of low intensity stroboscopic illumination (150 flashes/min), and three periods of no stress. All stressors were 10-14 h of duration and were applied individually and continuously, day and night.

On the basis of their sucrose intakes following 2 weeks of stress, both CON and STR groups were divided further into matched subgroups ( $n=8$ per group), which for the next 5 weeks received once-daily intraperitoneal administration of vehicle (saline, $1 \mathrm{ml} / \mathrm{kg}$ ), imipramine $\mathrm{HCl}(10 \mathrm{mg} / \mathrm{kg})$, rivastigmine $(2 \mathrm{mg} / \mathrm{kg})$, donepezil $(0.3 \mathrm{mg} / \mathrm{kg})$ or memantine $(5 \mathrm{mg} / \mathrm{kg})$. The drugs were administered at approximately $10.00 \mathrm{~h}$ and the weekly sucrose tests were carried out $24 \mathrm{~h}$ following the previous drug injections. After 5 weeks, all drug treatments were terminated and $24 \mathrm{~h}$ later, the animals were 
A Timelines for CMS

Weeks of stress

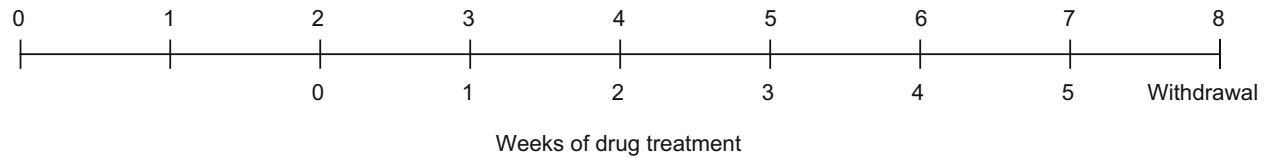

B Timelines for behavioural tests (Week 8)

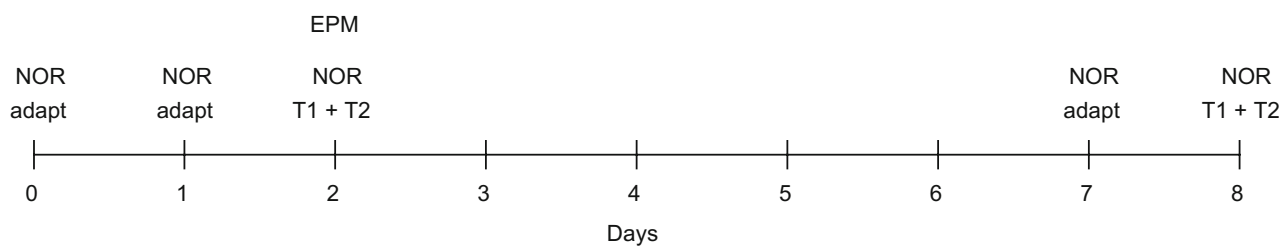

Fig. 1 Experimental timelines. a Timelines for CMS. Before the onset of CMS (week 0), animals were adapted for 2 weeks to laboratory and housing conditions followed by 7 weeks of baseline sucrose consumption tests. CMS (or no stress for the control group) was administered for 8 weeks, with drug treatment (saline, rivastigmine, donepezil, memantine or imipramine) administered daily for 5 weeks, beginning after 2 weeks of CMS, followed by a week of drug withdrawal. Sucrose consumption tests were conducted weekly, from

individually removed from their housing rooms to another room for testing in elevated plus maze and novel object recognition tests (see below). At least $15 \mathrm{~min}$ was allowed for habituation to the new environment before the behavioural test. After completing these tests, the animals were returned to their housing rooms and the CMS procedure was continue for a further week. After 1 week of drug withdrawal, the novel object recognition test was repeated. Stress was continued throughout the entire period of drug treatment and withdrawal. On the night before behavioural tests, animals received tilting or no stress; after the tests, scheduled stressors were applied (Fig. 1).

The study was run as two replications, the first including saline (SAL), imipramine (IMI) and rivastigmine (RIV) groups, and the second including SAL, donepezil (DON) and memantine (MEM) groups.

\section{Behavioural tests}

\section{Elevated plus maze (EPM)}

The animals were tested in non-transparent apparatus, which consisted of two open $(50 \times 11 \mathrm{~cm})$ and two closed $(50 \times 11 \times 40 \mathrm{~cm})$ arms. The apparatus was elevated $50 \mathrm{~cm}$ above the floor and was illuminated by two $25 \mathrm{~W}$ bulbs located beneath the open arms. The animal was individually placed in the centre of the apparatus, and the number of entries into open and closed arms was manually recorded during a 5-min test. An arm entry was defined as a rat having entered an arm with all four legs.
10.00 to 11.00 on Tuesdays. b Timelines for behavioural tests, conducted in the final week, following withdrawal after the 5 weeks of drug treatment. The first adaptation to the novel object recognition (NOR) apparatus (NOR adapt) took place 1 day before last drug dose. NOR trials (T1 and T2) and elevated plus maze (EPM) tests took place on the days shown. CMS continued throughout the entire period: on the night before behavioural tests, animals received tilting or no stress; after the tests, scheduled stressors were applied. See text for further details

\section{Novel object recognition (NOR)}

The animals were tested in non-transparent open field $(100 \mathrm{~cm}$ in diameter, $35 \mathrm{~cm}$ high, with the floor divided into painted 16-cm squares). After 10-min adaptation sessions on two successive days, the animals were allowed to explore two identical objects (white cylinders, $7 \mathrm{~cm}$ in diameter, $11 \mathrm{~cm}$ high) for the time required to complete $15 \mathrm{~s}$ of exploration of both objects ( $\mathrm{T} 1$ session). In a retention trial conducted $1 \mathrm{~h}$ later (T2 session), one of the objects presented previously was replaced by a novel object (black prism, $5 \mathrm{~cm}$ wide, $14 \mathrm{~cm}$ high). Rats were returned to the open field for $5 \mathrm{~min}$ and the duration of exploration of each object (i.e. sitting in close proximity to the objects, sniffing or touching them) was measured by a trained observer who was blind to drug treatment. A NOR index was calculated according to the following formula: time of novel object exploration divided by time of novel plus familiar object exploration, multiplied by 100 . During NOR sessions, the number of line crossings was recorded as a measure of locomotor activity.

\section{Drugs}

Drugs used were imipramine $\mathrm{HCl}$ (RBI, Natic, MA, USA), rivastigmine, donepezil and memantine (Sequoia Research Products Ltd, Pangbourne, UK). All drugs were dissolved in $0.9 \%$ sterile saline, which was used as a vehicle control treatment. The doses were selected on the basis of data in the literature and our preliminary experiments showing their efficacy in the behavioural assays used in this study. Doses were 
calculated as the salts, and all injections were made in a volume of $1 \mathrm{ml} / \mathrm{kg}$ of body weight.

\section{Statistical analysis}

Initial analyses confirmed that the two saline groups did not differ significantly on any parameter. Therefore, these two groups were combined for the purposes of analysis and (with one exception) display. Data were analysed by analysis of variance (anova) with the between-groups factors stress (CON vs. STR) and drug (SAL, IMI, RIV, DON, MEM). In some analyses, a further within-subjects factor was included, as described below. Significant interactions were followed up with lower-order anovas and Bonferroni tests, or $t$ tests, as appropriate.

\section{Results}

\section{Body weight}

Animals were weighed at four time points, the start of the stress procedure (week 0 : overall mean body weight $=$ $330 \mathrm{~g}$ ), after 2 weeks of CMS (week 2), after 5 weeks of CMS plus drug treatment (week 7), and after a further week of CMS during drug withdrawal (week 8). Anova showed a significant effect of drug $[\mathrm{F}(4,86)=3.05, p<0.05]$ and significant drug $\times$ weeks $[\mathrm{F}(12,258)=26.8, p<0.001]$ and stress $\times$ weeks $[\mathrm{F}(3258)=8.02, p<0.001]$ interactions, while the main effect of stress and the stress $\times$ drug and stress $\times$ drug $\times$ weeks interactions were nonsignificant [all Fs $<1$ ]. Further analysis showed that STR animals were a little heavier than CON at baseline but gained less weight than CON during the first 2 weeks of stress (mean weight gain 13 vs. 24 g), such that that the two groups were very similar in body weight (within $3 \mathrm{~g}$ ) thereafter, and that during the 5-week period of drug treatment, the SAL and DON groups each gained a mean of $28 \mathrm{~g}$, the RIV and MEM groups gained significantly less weight (mean of $12 \mathrm{~g}$ ), while the IMI group lost $16 \mathrm{~g}$.

\section{Sucrose intake}

Sucrose intakes are shown in Fig. 2, which for clarity shows the results of the two experiments separately. Anova confirmed a significant stress $\times$ drug $\times$ weeks interaction $[\mathrm{F}(32$, $688)=3.15, p<0.001]$. This results from the following effects:

(i) All STR groups showed a decrease in sucrose intake during weeks 1 and 2. In a further analysis, sucrose intake was expressed as a function of body weight ( $\mathrm{g}$ sucrose/kg body weight). Anova confirmed that sucrose intake was also significantly lower at week 2 when expressed in this way [stress $\times$ weeks interaction: $\mathrm{F}(1$, 94) $=117.3, p<0.001$; results not shown].

(ii) All CON groups maintained a steady high level of sucrose intake throughout the study, with the exception of the CON-MEM group, for which intake fell during the first week of drug treatment (week 3) and remained at roughly the same level thereafter.

(iii) The STR-IMI, STR-RIV and STR-DON groups all recovered to control levels of intake. This occurred at week 3 of drug treatment (i.e. week 5 of CMS) in the RIV and DON groups and week 5 of drug treatment (i.e. week 7 of CMS) in the IMI group.

(iv) The STR-MEM group did not recover. A separate Anova confined to the two MEM groups for the period weeks 3-6 confirmed that the effect of stress remained significant despite the decreased intake in the $\mathrm{CON}$ group $[\mathrm{F}(1,14)=11.56, p<0.001]$ and there was no significant stress $\times$ weeks interaction $[\mathrm{F}(5,70)=0.4]$.

\section{Elevated plus-maze}

In the EPM, there was a pronounced decrease in open arm entries in the STR-SAL group relative to the STR-CON group (Fig. 3, upper panel: $\mathrm{t}(30)=5.12, p<0.001$ ), but there was no significant effect of stress in any of the drug-treated groups: that is, the effect of stress was reversed by all four drug treatments [stress $\times$ drug interaction: $\mathrm{F}(1,86)=3.60, p<0.01]$. Results were similar for open arm time (not shown). There were some smaller effects on closed arm entries with no clear pattern [Fig. 3, lower panel; drug $\times$ stress interaction: $\mathrm{F}(4$, $86)=3.70, p<0.01]$. Total entries did not differ significantly between groups.

\section{Novel object recognition}

In the NOR test (Fig. 4, upper panels), SAL-treated stressed animals showed a marked decrease, relative to SAL-treated controls, in exploration of the novel object, which was highly significant in both tests $[\mathrm{t}(1,30)=3.85$ and $4.47, p<0.001]$. Behaviour was normalized by all four drug treatments [stress $\times$ drug interaction: $\mathrm{F}(4,86)=3.40, p<0.02]$. The stress $\times$ drug $\times$ tests interaction was nonsignificant $[\mathrm{F}(4,86)=1.1]$, indicating that stress $\times$ drug interactions were similar in the two tests. However, visual inspection suggests that the effect of RIV to reverse the effect of stress was present in the first test but not the second, and a further post hoc test confirmed that the difference between CON and STR RIV-treated animals was marginally significant in test $2[\mathrm{t}(1,14)=2.30, p<0.05]$.

Locomotor activity was not significantly affected by stress or drugs in either test [Fig. 4, lower panels; max F-value for main effects and stress $\times$ drug interactions $=1.16$ ]. 
Fig. 2 Sucrose intake in 60-min weekly tests by non-stressed control groups $(C O N)$ or animals exposed for 8 weeks to chronic mild stress $(C M S)$. Drugs were administered for 5 weeks (weeks 3-7). The upper panel shows effects of saline $(S A L)$, imipramine $(I M I)$ and rivastigmine (RIV); the lower panel shows effects of saline $(S A L)$, donepezil $(D O N)$ and memantine (MEM).

Values are group means. Error bars and significance indicators are omitted for clarity
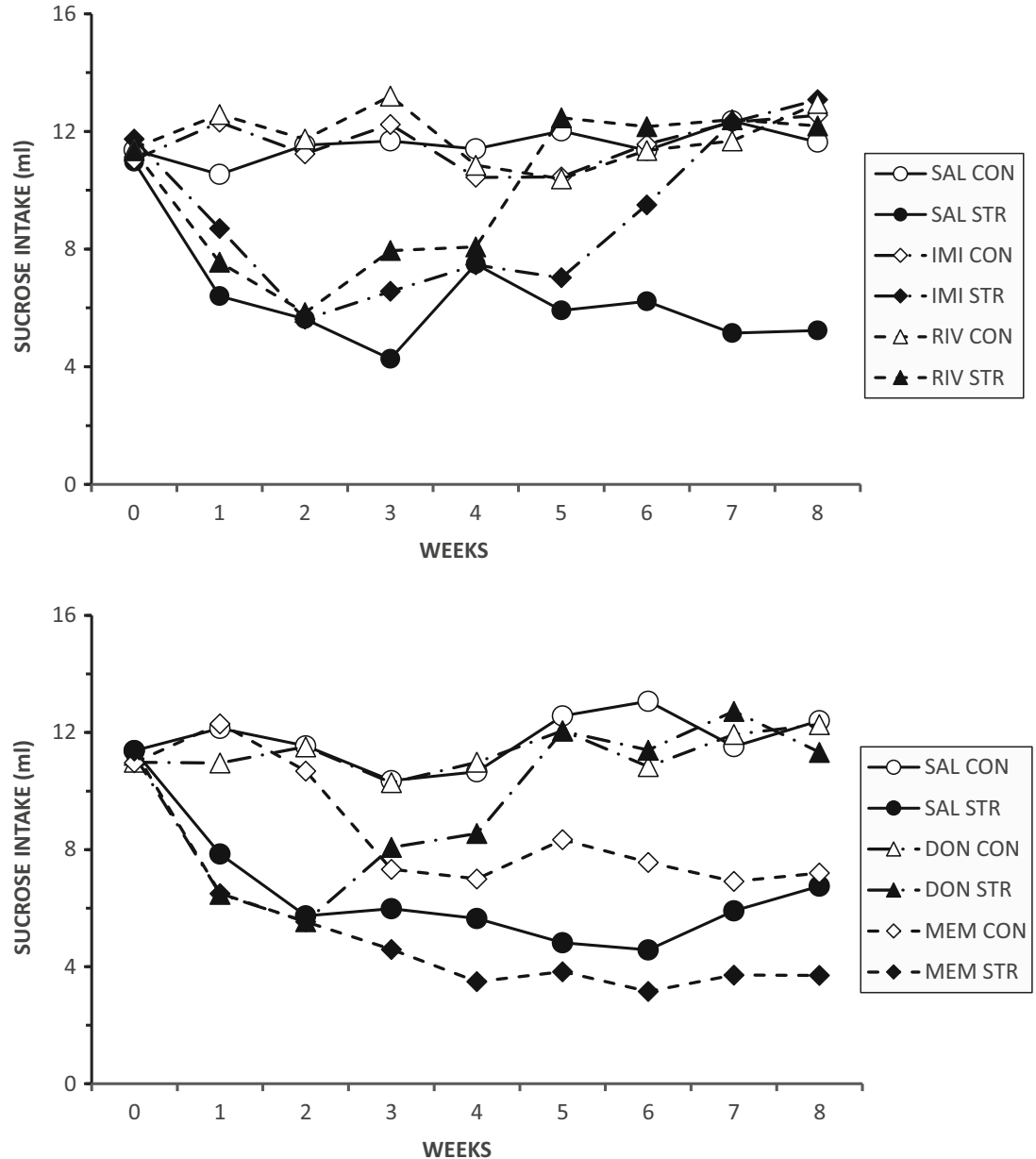

\section{Discussion}

Chronic mild stress caused a typical anhedonic effect in the sucrose intake test Willner 1997, 2005), as well as an anxiogenic effect in the elevated plus maze and cognitive impairment in the object recognition test. All of these effects were reversed by the prototypical antidepressant drug imipramine. The interpretation of a decrease in sucrose intake as anhedonia has been extensively discussed, and is supported by the demonstration that this effect is independent of effects of stress on body weight (as confirmed here), by CMSinduced impairments in other tests of rewarded behaviour such as place conditioning and brain stimulation reward, and by the ineffectiveness of anxiolytic drugs such as benzodiazepines to reverse these impairments (Willner 1997, 2005).

All three anti-dementia drugs were effective in reversing CMS effects in the open field and object recognition tests. However, while the anticholinesterases rivastigmine and donepezil also reversed stress-induced anhedonia (and so were comparable to imipramine in their overall effects), the NMDA antagonist memantine did not. The onset of action of donepezil and rivastigmine was somewhat faster than that of imipramine (recovery in 3 vs. 5 weeks) but these differences may be dose-related. A limitation of the present study is that it was conducted in young animals. This was a deliberate choice, to enable a clean evaluation of the interaction between drug effects and CMS while avoiding complications arising from age-associated cognitive decline. However, as antidementia drugs are typically prescribed to older patients, a replication of the study in older animals would be warranted.

Anxiogenic effects, while not universally observed, have frequently been described in animals subjected to chronic mild stress, and, like anhedonic effects, are reversed by chronic antidepressant treatment (e.g. Surget et al. 2008; Farley et al. 2010; Wang et al. 2014). We are unaware of any previous studies of the effects of anticholinesterases or NMDA antagonists on anxiety-like behaviour in the CMS model. In normal animals, a recent study found that chronic administration of fluoxetine increased hippocampal AChE activity, while knockdown of $\mathrm{AChE}$ in the hippocampus increased anxietylike behaviour in the elevated plus-maze (Mineur et al. 2013), suggesting an anxiogenic effect of hippocampal AChE inhibition. However, anxiolytic-like effects of systemically administered AChE inhibitors have also been reported (e.g. Cutuli et al. 2008; Chen et al. 2011; Zarrindast et al. 2011). Results with memantine are similarly mixed, with some 

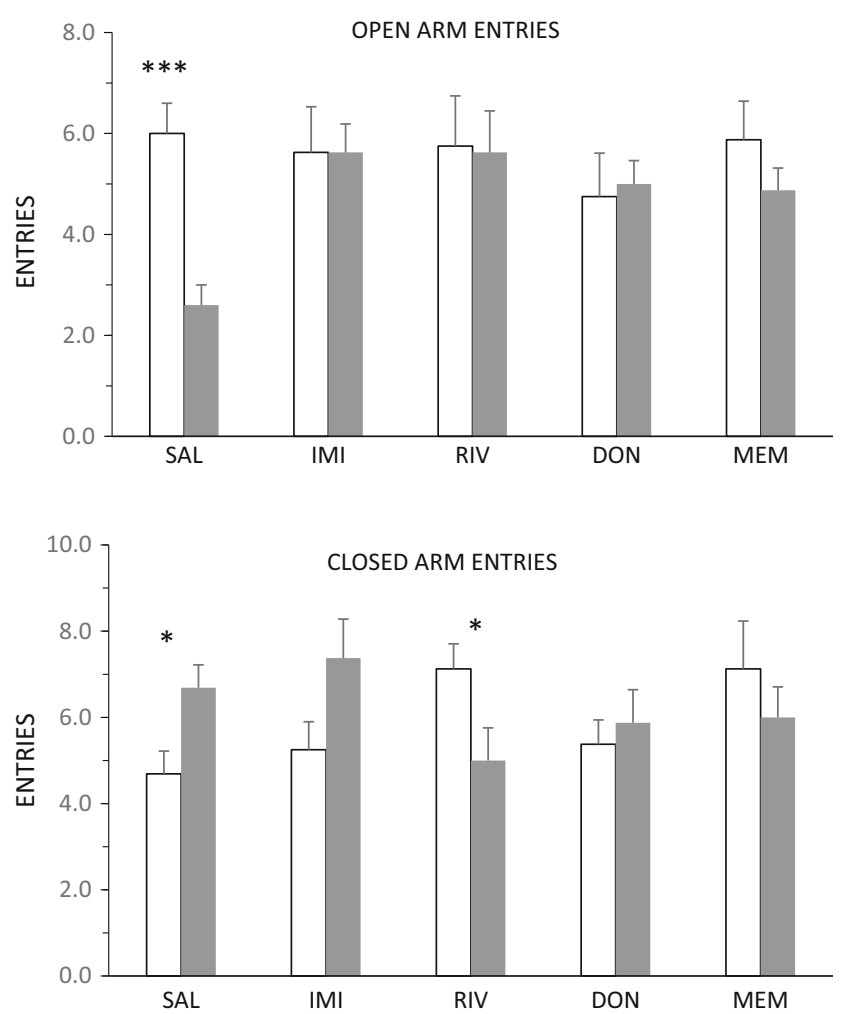

Fig. 3 Number of entries to the open (upper panel) and closed (lower panel) arms of the elevated plus maze in non-stressed animals (white bars) or animals subjected for 7 weeks to CMS (grey bars). Both groups received daily administration, for 5 weeks, of saline $(S A L)$, imipramine $(I M I)$, rivastigmine $(R I V)$, donepezil $(D O N)$ or memantine $(M E M)$. Values are means + standard error. ${ }^{*} p<0.05 ;{ }^{* * *} p<0.001$, control vs. CMS

studies reporting anxiolytic-like effects (Bertoglio and Carobrez 2003; Minkeviciene et al. 2008) and others finding memantine to be ineffective as an anxiolytic (Karcz-Kubicha et al. 1997; Kotlinska and Bochenski 2008; Koltunowska et al. 2013). As noted in the Introduction, in the present study, the purpose of testing animals in the elevated plus-maze was primarily to confirm that drugs were administered at behaviourally active doses. Further studies of the potential anxiolytic activity of these drugs in the CMS model and other well-validated models of depression could provide a clearer picture of their potential relevance to mixed anxietydepression conditions.

The impairment of object recognition performance by CMS, and its remediation by chronic antidepressant treatment, is consistent with earlier findings (Orsetti et al. 2007; Elizalde et al. 2008; Briones et al. 2012; Solas et al. 2013). In aged animals, CMS also increases biochemical markers associated with Alzheimer's disease (El-faramawy et al. 2009; Briones et al. 2012; Solas et al. 2013; Yang et al. 2014), indicating that, in addition to its utility as an animal model of depression, the CMS procedure may have value as a model to investigate the early stages of dementia (e.g. Cuadrado-Tejedor et al. 2012; Lisowski et al. 2013). Our observation that imipramine,
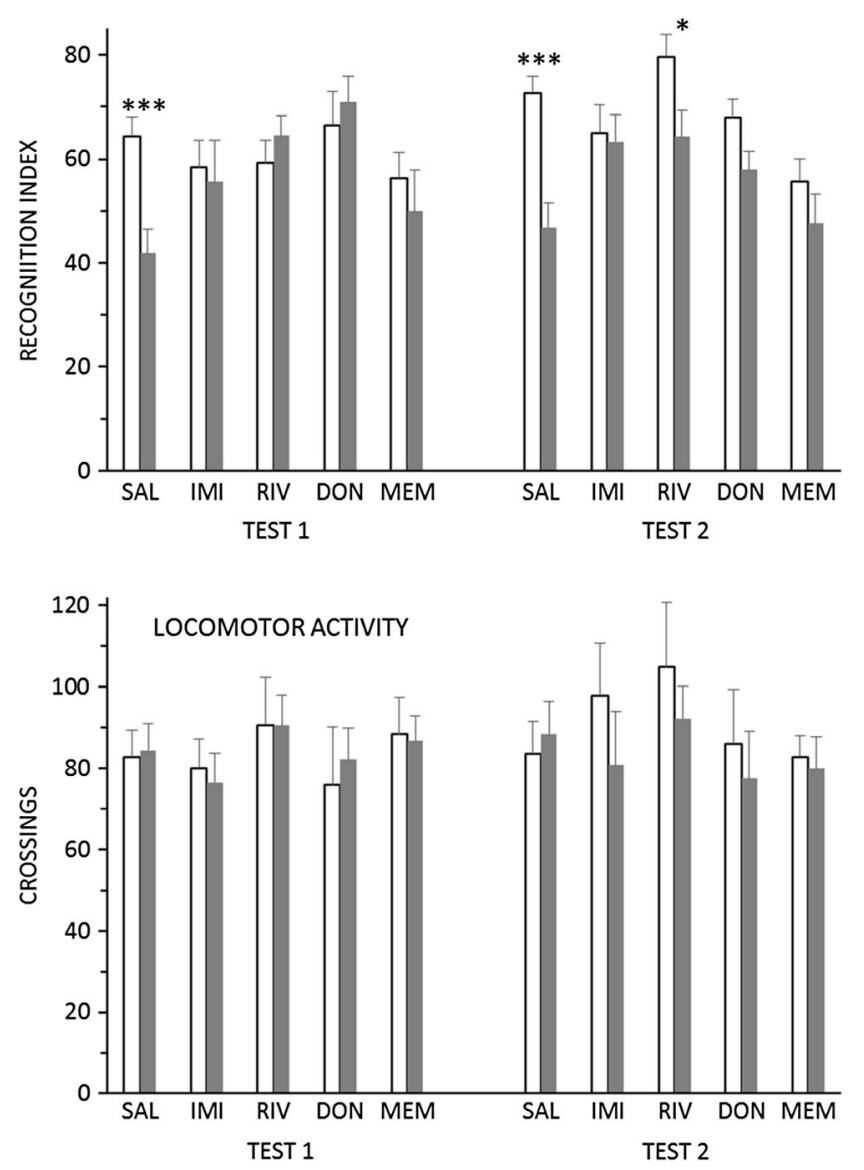

Fig. 4 Behaviour in the novel object recognition (NOR) test by nonstressed animals (white bars) or animals subjected for 7 and 8 weeks to CMS (grey bars). Upper panel: NOR index (\%); lower panel: number of lines crossed. Both groups received daily administration of saline $(S A L)$, imipramine $(I M I)$, rivastigmine $(R I V)$, donepezil $(D O N)$ or memantine $(M E M)$. Test 1 followed 5 weeks of drug administration; test 2 followed 1 week of drug withdrawal. Values are means + standard error. ${ }^{*} p<0.05$; $* * * p<0.001$, control vs. CMS

rivastigmine and donepezil reversed both CMS-induced anhedonia and cognitive impairment, while memantine reversed only the cognitive impairment, suggests the possibility that different mechanisms may mediate these two behavioural effects of CMS. Indeed, in the final set of tests, following a week of drug withdrawal, there was a suggestion of a double dissociation: memantine reversed the impairment of object recognition and rivastigmine reversed anhedonia, but not vice versa. (However, the lack of effect of rivastigmine results from an increase in the discrimination index in the control group (Fig. 4) and so may not be reliable.) While there is a substantial literature describing the mechanisms involved in CMSinduced anhedonia and its reversal by antidepressant drugs (reviewed by Willner et al. 2013), the mechanisms underlying CMS-induced cognitive impairment remain to be elucidated.

The absence of an antidepressant-like effect of memantine in the present study, in the context of evidence of behavioural activity of memantine in other tests, is consistent with clinical evidence that memantine is not an effective antidepressant 
(Sani et al. 2012). Memantine is different in this respect from ketamine, for which antidepressant properties are well established: the explanation may be that while both drugs are NMDA receptor antagonists, they differ in the effect on glutamatergic neurotransmission and downstream intracellular signaling: for example, ketamine, but not memantine, increases hippocampal BDNF expression (Gideons et al. 2014). In contrast to the present results (and the clinical outcomes), two previous studies have reported positive antidepressantlike effects of memantine in the CMS model (Quan et al. 2011; Réus et al. 2012). The discrepancy may be dose-related: the earlier studies used a considerably higher dose of memantine ( 20 vs. $5 \mathrm{mg} / \mathrm{kg}$ ) that is associated with adverse side effects (Creeley et al. 2006, 2008).

As noted earlier, there is a mixed clinical picture regarding potential antidepressant effects of AChE inhibitors (see Introduction). However, the fact that there are any positive reports could be considered surprising, in the context of an extensive earlier literature reporting that anticholinesterases exacerbate depression (Janowsky et al. 1974; Janowsky and Risch 1984). The variable clinical outcomes may reflect the fact that, by increasing synaptic levels of acetylcholine, $\mathrm{AChE}$ inhibitors increase stimulation of both muscarinic and nicotinic acetylcholine receptors, and these two receptors may be differentially involved in depression. Muscarinic receptor antagonists appear to have antidepressant properties: there is an extensive older literature describing antidepressant effects of atropine (Hoch and Mauss 1932; Janowsky and Risch 1984), and a more recent literature reporting similar effects of scopolamine (Furey and Drevets 2006; Hasselmann 2014). Consistent with the clinical literature, atropine (Papp et al. 1996) and scopolamine (Geoffroy et al. 1990) have also been found to exert antidepressant-like effects in the CMS and learned helplessness models, respectively. Conversely, antidepressant-like effects in these two models have been reported for nicotinic receptors agonists (Ferguson et al. 2000; Andreasen et al. 2011), and there is current interest in the clinical potential of nicotinic agonists as antidepressants (Philip et al. 2010; Zurkovsky et al. 2013). Thus, it is likely that the antidepressant-like effects of donepezil and rivastigmine that were observed in the present study would be blocked by nicotinic, but not muscarinic, antagonists; further mechanistic studies are needed to test this prediction. More generally, it seems likely that the outcome of anticholinesterase treatment of depression may depend on the balance of stimulation at muscarinic and nicotinic receptors, which might vary as a function of drug dose, mood status, and baseline level of cholinergic activity. Further investigation is needed to elucidate these relationships.

A single controlled trial of donepezil found no benefit of adding donepezil to antidepressant maintenance for older adults with normal cognition or mild cognitive impairment (Reynolds et al. 2011). However, positive antidepressant effects in patients with Alzheimer's disease have been reported in two open trials of a rivastigmine transdermal patch (Spalletta et al. 2013, 2014) and a controlled trial of oral rivastigmine (Mowla et al. 2007). Consistent with these clinical data and the present observations, chronic administration of rivastigmine also had characteristic antidepressant-like and anxiolytic effects in olfactory bulbectomized animals (Islam et al. 2014). Rivastigmine also restored hippocampal neurogenesis and associated enzyme activities in bulbectomized animals; and all of these effects were blocked by co-treatment with a $5 \mathrm{HT} 1 \mathrm{~A}$ receptor antagonist (Islam et al. 2014). Destruction of cholinergic neurons is known to decrease hippocampal 5HT levels (Nakamura et al. 1992), suggesting that an adequate level of cholinergic activity is necessary for normal activity at hippocampal 5HT terminals, and that rivastigmine may enhance hippocampal $5 \mathrm{HT}$ activity in a manner comparable to conventional antidepressants (Willner et al. 2013). Alongside these earlier data, the present results provide grounds for cautious optimism that there may be a place for $\mathrm{AChE}$ inibitors in the treatment of depression, though realistically, this would in practice be restricted to older patients experiencing, or at risk of, cognitive decline.

Open Access This article is distributed under the terms of the Creative Commons Attribution 4.0 International License (http:// creativecommons.org/licenses/by/4.0/), which permits unrestricted use, distribution, and reproduction in any medium, provided you give appropriate credit to the original author(s) and the source, provide a link to the Creative Commons license, and indicate if changes were made.

\section{References}

Andreasen JT, Henningsen K, Bate S, Christiansen S, Wiborg O (2011) Nicotine reverses anhedonic-like response and cognitive impairment in the rat chronic mild stress model of depression: comparison with sertraline. J Psychopharmacol 25:1134-1141

Aziz R, Steffens DC (2013) What are the causes of late-life depression? Psychiatr Clin N Am 36:497-516

Belzung C (2014) Innovative drugs to treat depression: did animal models fail to be predictive or did clinical trials fail to detect effects? Neuropsychopharmacology 39:1041-1051

Bertoglio LJ, Carobrez AP (2003) Anxiolytic-like effects of NMDA/ glycine-B receptor ligands are abolished during the elevated plusmaze trial 2 in rats. Psychopharmacology (Berlin) 170:335-342

Briones A, Gagno S, Martisova E, Dobarro M, Aisa B, Solas M, Tordera R, Ramírez M (2012) Stress-induced anhedonia is associated with an increase in Alzheimer's disease-related markers. Br J Pharmacol 165:897-907

Calati R, Salvina Signorelli M, Balestri M, Marsano A, De Ronchi D, Aguglia E, Serretti A (2013) Antidepressants in elderly: metaregression of double-blind, randomized clinical trials. J Affect Disord 147:1-8

Chen WQ, Yuan L, Xue R, Li YF, Su RB, Zhang YZ, Li J (2011) Repeated exposure to chlorpyrifos alters the performance of adolescent male rats in animal models of depression and anxiety. Neurotoxicology 32:355-361 
Creeley C, Wozniak DF, Labruyere J, Taylor GT, Olney JW (2006) Low doses of memantine disrupt memory in adult rats. J Neurosci 26 : 3923-3932

Creeley CE, Wozniak DF, Nardi A, Farber NB, Olney JW (2008) Donepezil markedly potentiates memantine neurotoxicity in the adult rat brain. Neurobiol Aging 29:153-167

Cuadrado-Tejedor M, Ricobaraza A, Frechilla D, Franco R, PérezMediavilla A, Garcia-Osta A (2012) Chronic mild stress accelerates the onset and progression of the Alzheimer's disease phenotype in Tg2576 mice. J Alzheimers Dis 28:567-578

Cummings JL, McRae T, Zhang R, Donepezil-Sertraline Study Group (2006) Effects of donepezil on neuropsychiatric symptoms in patients with dementia and severe behavioral disorders. Am J Geriatr Psychiatr 14:605-612

Cutuli D, Foti F, Mandolesi L, De Bartolo P, Gelfo F, Federico F, Petrosini L (2008) Cognitive performance of healthy young rats following chronic donepezil administration. Psychopharmacology (Berlin) 197:661-673

Diazgranados N, Ibrahim L, Brutsche NE, Newberg A, Kronstein P, Khalife S, Kammerer WA, Quezado Z, Luckenbaugh DA, Salvadore G, Machado-Vieira R, Manji HK, Zarate CA Jr (2010) A randomized add-on trial of an N-methyl-D-aspartate antagonist in treatment-resistant bipolar depression. Arch Gen Psychiatry 67: 793-802

El-faramawy YA, El-banouby MH, Sergeev P, Mortagy AK, Amer MS, Abdel-tawab AM (2009) Changes in glutamate decarboxylase enzyme activity and tau-protein phosphorylation in the hippocampus of old rats exposed to chronic mild stress: reversal with the neuronal nitric oxide synthase inhibitor 7-nitroindazole. Pharmacol Biochem Behav 91:339-344

Elizalde N, Gil-Bea FJ, Ramírez MJ, Aisa B, Lasheras B, Del Rio J, Tordera RM (2008) Long-lasting behavioral effects and recognition memory deficit induced by chronic mild stress in mice: effect of antidepressant treatment. Psychopharmacology (Berlin) 199:1-14

Farley S, Apazoglou K, Witkin JM, Giros B, Tzavara ET (2010) Antidepressant-like effects of an AMPA receptor potentiator under a chronic mild stress paradigm. Int J Neuropsychopharmacol 13: 1207-1218

Ferguson SM, Brodkin JD, Lloyd GK, Menzaghi F (2000) Antidepressant-like effects of the subtype-selective nicotinic acetylcholine receptor agonist, SIB-1508Y, in the learned helplessness rat model of depression. Psychopharmacology (Berlin) 152:295-303

Furey ML, Drevets WC (2006) Antidepressant efficacy of the antimuscarinic drug scopolamine: a randomized, placebocontrolled clinical trial. Arch Gen Psychiatry 63:1121-1129

Geoffroy M, Scheel-Krüger J, Christensen AV (1990) Effect of imipramine in the "learned helplessness" model of depression in rats is not mimicked by combinations of specific reuptake inhibitors and scopolamine. Psychopharmacology (Berlin) 101:371-375

Gideons ES, Kavalali ET, Monteggia LM (2014) Mechanisms underlying differential effectiveness of memantine and ketamine in rapid antidepressant responses. Proc Natl Acad Sci U S A 111:8649-8654

Hamani C, Mayberg H, Stone S, Laxton A, Haber S, Lozano AM (2011) The subcallosal cingulate gyrus in the context of major depression. Biol Psychiatry 69:301-308

Hasselmann H (2014) Scopolamine and depression: a role for muscarinic antagonism? CNS Neurol Disord Drug Targets 13:673-683

Hoch PH, Mauss W (1932) Atropin Behandling bei Geisteckvankheiten. Arch Gen Psychatry 97:546-552

Holtzheimer PE, Mayberg HS (2011) Stuck in a rut: rethinking depression and its treatment. Trends Neurosci 34:1-9

Holtzheimer PE 3rd, Meeks TW, Kelley ME, Mufti M, Young R, McWhorter K, Vito N, Chismar R, Quinn S, Dey S, Byrd EH, McDonald WM (2008) A double blind, placebo-controlled pilot study of galantamine augmentation of antidepressant treatment in older adults with major depression. Int J Geriatr Psychiatry 23: 625-631

Islam MR, Moriguchi S, Tagashira H, Fukunaga K (2014) Rivastigmine improves hippocampal neurogenesis and depression-like behaviors via 5-HT1A receptor stimulation in olfactory bulbectomized mice. Neuroscience 272:116-130

Janowsky DS, Risch SC (1984) Cholinomemetic and anticholinergic drugs used to ingestigae an acetylcholine hypothesis of affective disorders and stress. Drug Dev Res 4:125-142

Janowsky DS, El-Yousef MK, Davis JM (1974) Acetylcholine and depression. Psychosom Med 36:248-257

Karcz-Kubicha M, Jessa M, Nazar M, Plaznik A, Hartmann S, Parsons CG, Danysz W (1997) Anxiolytic activity of glycine-B antagonists and partial agonists - no relation to intrinsic activity in the patch clamp. Neuropharmacology 36:1355-1367

Kok RM, Nolen WA, Heeren TJ (2012) Efficacy of treatment in older depressed patients: a systematic review and meta-analysis of doubleblind randomized controlled trials with antidepressants. J Affect Disord 141:103-115

Koltunowska D, Gibula-Bruzda E, Kotlinska JH (2013) The influence of ionotropic and metabotropic glutamate receptor ligands on anxietylike effect of amphetamine withdrawal in rats. Prog Neuropsychopharmacol Biol Psychiatry 45:242-249

Kotlinska J, Bochenski M (2008) The influence of various glutamate receptors antagonists on anxiety-like effect of ethanol withdrawal in a plus-maze test in rats. Eur J Pharmacol 598:57-63

Lenze EJ, Skidmore ER, Begley AE, Newcomer JW, Butters MA, Whyte EM (2012) Memantine for late-life depression and apathy after a disabling medical event: a 12 -week, double-blind placebo-controlled pilot study. Int J Geriatr Psychiatry 27:974-980

Lisowski P, Wieczorek M, Goscik J, Juszczak GR, Stankiewicz AM, Zwierzchowski L, Swiergiel AH (2013) Effects of chronic stress on prefrontal cortex transcriptome in mice displaying different genetic backgrounds. J Mol Neurosci 50:33-57

Maratha SR, Mahadevan N (2012) Memory enhanding activity of naringin in unstressed and stressed mice: possible cholinergic and nitriergic modulation. Neurochem Res 37:2206-2212

Mayberg HS (2009) Targeted electrode-based modulation of neural circuits for depression. J Clin Invest 119:717-725

McDermott CL, Gray SL (2012) Cholinesterase inhibitor adjunctive therapy for cognitive impairment and depressive symptoms in older adults with depression. Ann Pharmacother 46:599-605

Mineur YS, Obayemi A, Wigestrand MB, Fote GM, Calarco CA, Li AM, Picciotto MR (2013) Cholinergic signaling in the hippocampus regulates social stress resilience and anxiety- and depression-like behavior. Proc Natl Acad Sci U S A 110:3573-3578

Minkeviciene R, Banerjee P, Tanila H (2008) Cognition-enhancing and anxiolytic effects of memantine. Neuropharmacology 54:10791085

Mowla A, Mosavinasab M, Haghshenas H, Borhani Haghighi A (2007) Does serotonin augmentation have any effect on cognition and activities of daily living in Alzheimer's dementia? A double-blind, placebo-controlled clinical trial. J Clin Psychopharmacol 27:484 487

Muhonen LH, Lönnqvist J, Juva K, Alho H (2008) Double-blind, randomized comparison of memantine and escitalopram for the treatment of major depressive disorder comorbid with alcohol dependence. J Clin Psychiatry 69:392-399

Nakamura S, Tani Y, Maeeno Y, Ishihara T, Ohno T (1992) Learning deficits after unilateral AF64A lesions in the rat basal forebrain: role of cholinergic and noncholinergic systems. Pharmacol Biochem Behav 42:119-130

Omranifard V, Shirzadi E, Samandari S, Afshar H, Maracy MR (2014) Memantine add on to citalopram in elderly patients with depression: a double-blind placebo-controlled study. J Res Med 19:525-530 
Orsetti M, Colella L, Dellarole A, Canonico PL, Ghi P (2007) Modification of spatial recognition memory and object discrimination after chronic administration of haloperidol, amitriptyline, sodium valproate or olanzapine in normal and anhedonic rats. Int $\mathrm{J}$ Neuropsychopharmacol 10:345-357

Papp M, Moryl E, Willner P (1996) Pharmacological validation of the chronic mild stress model of depression. Eur J Pharmacol 296:129 136

Philip NS, Carpenter LL, Tyrka AR, Price LH (2010) Nicotinic acetylcholine receptors and depression: a review of the preclinical and clinical literature. Psychopharmacology (Berlin) 212:1-12

Quan MN, Zhang N, Wang YY, Zhang T, Yang Z (2011) Possible antidepressant effects and mechanisms of memantine in behaviors and synaptic plasticity of a depression rat model. Neuroscience 182:8897

Réus GZ, Abelaira HM, Stringari RB, Fries GR, Kapczinski F, Quevedo J (2012) Memantine treatment reverses anhedonia, normalizes corticosterone levels and increases BDNF levels in the prefrontal cortex induced by chronic mild stress in rats. Metab Brain Dis 27:175-182

Reynolds CF 3rd, Butters MA, Lopez O, Pollock BG, Dew MA, Mulsant BH, Lenze EJ, Holm M, Rogers JC, Mazumdar S, Houck PR, Begley A, Anderson S, Karp JF, Miller MD, Whyte EM, Stack J, Gildengers A, Szanto K, Bensasi S, Kaufer DI, Kamboh MI, DeKosky ST (2011) Maintenance treatment of depression in old age: a randomized, double-blind, placebo-controlled evaluation of the efficacy and safety of donepezil combined with antidepressant pharmacotherapy. Arch Gen Psychiatry 68:51-60

Rozzini L, Vicini Chilovi B, Bertoletti E, Trabucchi M, Padovani A (2007) Acetylcholinesterase inhibitors and depressive symptoms in patients with mild to moderate Alzheimer's disease. Aging Clin Exp Res 19:220-223

Sani G, Serra G, Kotzalidis GD, Romano S, Tamorri SM, Manfredi G, Caloro M, Telesforo CL, Caltagirone SS, Panaccione I, Simonetti A, Demontis F, Serra G, Girardi P (2012) The role of memantine in the treatment of psychiatric disorders other than the dementias: a review of current preclinical and clinical evidence. CNS Drugs 26:663-690

Smith EG, Deligiannidis KM, Ulbricht CM, Landolin CS, Patel JK, Rothschild AJ (2013) Antidepressant augmentation using the Nmethyl-D-aspartate antagonist memantine: a randomized, doubleblind, placebo-controlled trial. J Clin Psychiatry 74:966-973

Solas M, Aisa B, Tordera RM, Mugueta MC, Ramírez MJ (2013) Stress contributes to the development of central insulin resistance during aging: implications for Alzheimer's disease. Biochim Biophys Acta 1832:2332-2339

Spalletta G, Gianni W, Giubilei F, Casini AR, Sancesario G, Caltagirone C, Cravello L (2013) Rivastigmine patch ameliorates depression in mild AD: preliminary evidence from a 6-month open-label observational study. Alzheimer Dis Assoc Disord 27:289-291

Spalletta G, Caltagirone C, Padovani A, Sorbi S, Attar M, Colombo D, Cravello L, E V O L U T I O N study Working Group (2014) Cognitive and affective changes in mild to moderate Alzheimer's disease patients undergoing switch of cholinesterase inhibitors: a 6month observational study. PLoS One 9(2):e89216

Surget A, Saxe M, Leman S, Ibarguen-Vargas Y, Chalon S, Griebel G, Hen R, Belzung C (2008) Drug-dependent requirement of hippocampal neurogenesis in a model of depression and of antidepressant reversal. Biol Psychiatry 64:293-301

Trivedi MH, Rush AJ, Wisniewski SR, Nierenberg AA, Warden D, Ritz L, Norquist G, Howland RH, Lebowitz B, McGrath PJ, ShoresWilson K, Biggs MM, Balasubramani GK, Fava M, STAR*D Study Team (2006) Evaluation of outcomes with citalopram for depression using measurement-based care in STAR*D: implications for clinical practice. Am J Psychiatry 163:28-40

Wang C, Li M, Sawmiller D, Fan Y, Ma Y, Tan J, Ren Y, Li S (2014) Chronic mild stress-induced changes of risk assessment behaviors in mice are prevented by chronic treatment with fluoxetine but not diazepam. Pharmacol Biochem Behav 116:116-128

Weisenbach SL, Boore LA, Kales HC (2012) Depression and cognitive impairment in older adults. Curr Psychiatry Rep 14:280-288

Willner P (1997) Validity, reliability and utility of the chronic mild stress (CMS) model of depression: a ten-year review and evaluation. Psychopharmacology 134:319-329

Willner P (2005) Chronic mild stress (CMS) revisited: consistency and behavioural-neurobiological concordance in the effects of CMS. Neuropsychobiology 52:90-110

Willner P, Scheel-Kruger J, Belzung C (2013) The neuropharmacology of depression and antidepressant treatment. Neurosci Biobehav Rev 37:2331-2371

Willner P, Belzung C, Scheel-Kruger J (2014) Resistance to antidepressant drugs: the case for a more predisposition-based and less hippocampocentric research paradigm. Behav Pharmacol 25:352 371

Yang C, Guo X, Wang GH, Wang HL, Liu ZC, Liu H, Zhu ZX, Li Y (2014) Changes in tau phosphorylation levels in the hippocampus and frontal cortex following chronic stress. Braz J Med Biol Res 47: 237-244

Zarate CA Jr, Singh JB, Carlson PJ, Brutsche NE, Ameli R, Luckenbaugh DA, Charney DS, Manji HK (2006a) A randomized trial of an Nmethyl-D-aspartate antagonist in treatment-resistant major depression. Arch Gen Psychiatry 63:856-864

Zarate CA Jr, Singh JB, Quiroz JA, De Jesus G, Denicoff KK, Luckenbaugh DA, Manji HK, Charney DS (2006b) A double-blind, placebo-controlled study of memantine in the treatment of major depression. Am J Psychiatry 163:153-155

Zarrindast MR, Sroushi A, Bananej M, Vousooghi N, Hamidkhaniha S (2011) Involvement of the dopaminergic receptors of the rat basolateral amygdala in anxiolytic-like effects of the cholinergic system. Eur J Pharmacol 672:106-112

Zurkovsky L, Taylor WD, Newhouse PA (2013) Cognition as a therapeutic target in late-life depression: potential for nicotinic therapeutics. Biochem Pharmacol 86:1133-1144 